\title{
Demand Forecasting: A Case Study in the Food Industry ${ }^{\star}$
}

\author{
Juliana C. Silva ${ }^{1[0000-0003-2835-4196]}$, Manuel C. \\ Figueiredo ${ }^{2[0000-0002-0483-1341]}$, and Ana C. Braga ${ }^{2[0000-0002-1991-9418]}$ \\ 1 DPS, School of Engineering, University of Minho \\ 2 ALGORITMI Centre, University of Minho, \\ 4710-057 Braga, Portugal \\ ju_silva21@hotmail.com, \{mcf,acb\}@dps.uminho.pt
}

\begin{abstract}
The use of forecasting methods is nowadays regarded as a business ally since it supports both the operational and the strategic decision making processes.

This paper is based on a research project aiming the development of demand forecasting models for a company (designated here by PR) that operates in the food business, more specifically in the delicatessen segment.

In particular, we focused on demand forecasting models that can serve as a tool to support production planning and inventory management at the company.

The analysis of the company's operations led to the development of a new demand forecasting tool based on a combination of forecasts, which is now being used and tested by the company.
\end{abstract}

Keywords: Forecasting demand - Exponential Smoothing - ARIMA . Combining forecasts.

\section{Introduction}

\subsection{The Company}

The PR Company already has more than half a century of history, presenting itself today as a reference company in the production and distribution of delicatessen.

From its foundation to the present, PR has specialized and transformed itself into a modern organization, with a professional management and equipped with the latest technologies, thus managing to anticipate the challenges and specificities of competitiveness and globalization never losing its roots in Portugal.

It should also be mentioned that PR is a company highly certified by several standards that attest Quality Management Systems (ISO 9001: 2008), the Environmental Management System (ISO 14001: 2004) and Food Safety Management

* This work has been supported by FCT - Fundação para a Ciência e Tecnologia within the Project Scope: UID/CEC/00319/2019 
Systems (ISO 22000: 2005). It is also internationally recognized by specific standards for the food industry, such as IFS - International Featured Standard, which strengthens its competitiveness in the global market.

The company's strategy is essentially a sustained business growth, always guaranteeing a quality of excellence to the consumer, assuming quality and safety as a priority of the business. In order to respond to market demand, PR presents a diverse portfolio of products, which can be grouped into six different product families as shown in Fig. 1,
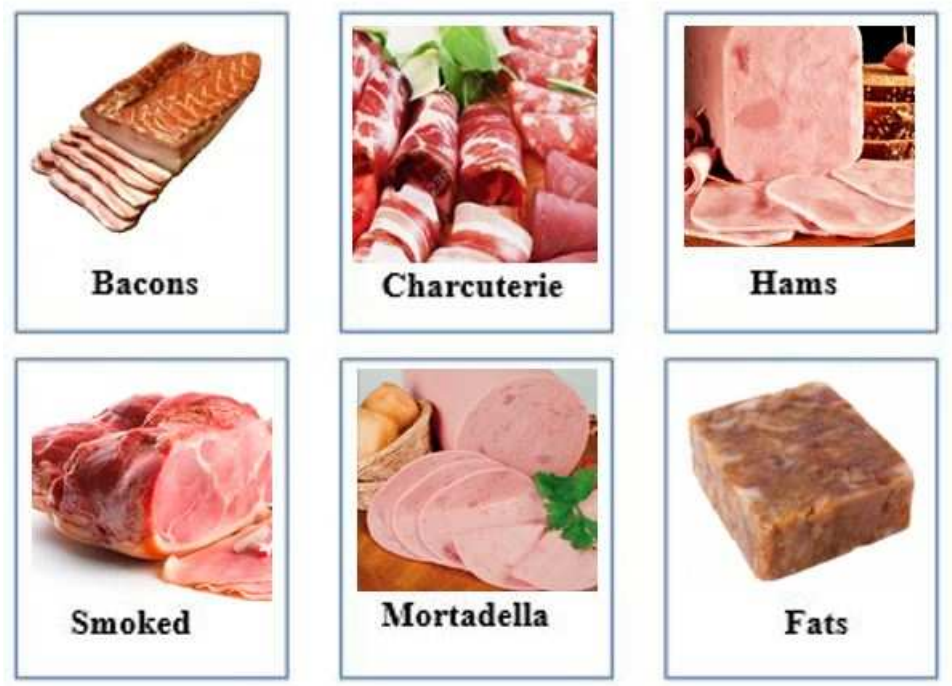

Fig. 1: Product families.

Currently, PR is present in the most diverse sectors of the national distribution: retail, cash \& carry, modern distribution and professional channels.

In addition to the domestic market, where it has been gaining strength and holding leading positions, PR has already achieved strong internationalization of its brand in countries such as: Angola, Brazil, France, Germany, Holland, Luxembourg, Mozambique, United Kingdom, Russia, South Africa and Sweden (Fig. 2).

\subsection{The Importance of Demand Forecasting in the Food Industry}

Due to the increasing level of competitiveness among companies, forecasting plays an important role in supply chain management, and the viability of a company is often dependent on the efficiency and accuracy of forecasts [14. Demand forecasts are beyond all strategic and planning decisions in any retail business as they directly affect the company's profitability and competitive position. 


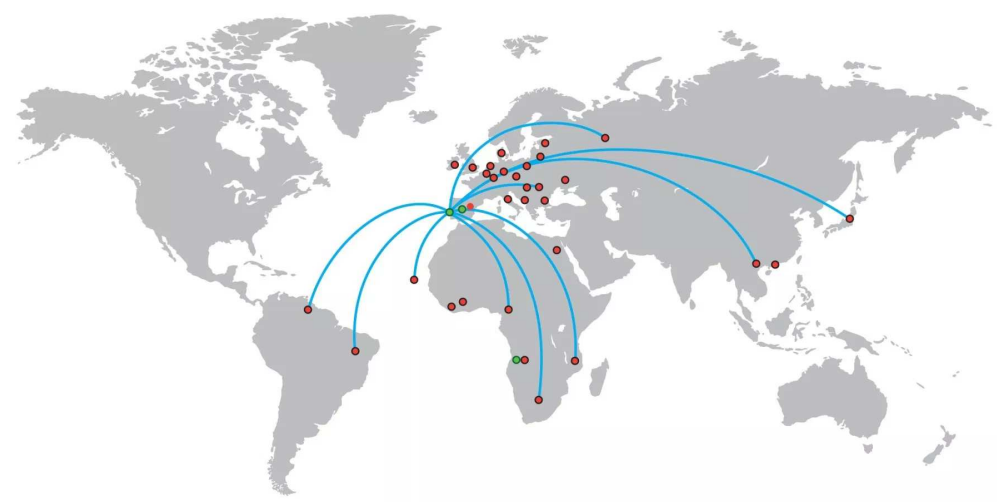

Fig. 2: Company markets.

For these reasons, the use of demand forecasting techniques is one of the fundamental supports in the planning and management of a company's supply chain [7].

Its importance becomes patent, since its outcome is used by many functions in the organization: they allow the financial department to estimate costs, levels of profit and capital needs; enable the sales department to obtain know-how of the sales volume of each product; the purchasing department may plan shortand long-term acquisitions; the marketing department can plan their actions and evaluate the impact of different marketing strategies on the sales volume and brand awareness, the logistics department that will be able to define the specific logistics needs and finally, the operations department that can manage and plan the purchase of machinery and materials, as well as the hiring of labor, in advance.

It is, therefore, consensual that the forecasts are very useful, and even essential for most companies. Accurate demand forecasts have the potential to increase profitability, improving the chain's efficiency and reducing waste.

This paper describes various demand forecasting models for products made by a food company. In the food business, a proper management of inventories involves numerous articles whose particular characteristics, namely perishability, are relevant. Bad decisions in this area can lead to large losses related to excess stock.

\section{Demand Forecasting}

\subsection{Demand Forecasting Methods}

Predicting demand is a fundamental activity, as it can reveal market trends and contribute to the strategic planning of the company. According to [1, demand forecasting is an essential tool to make the decision process faster and safer. 
There are several techniques available to support analysts in forecasting demand. Although these techniques have substantial differences, there are common characteristics:

- They generally assume that the causes that have influenced demand in the past will continue to act in the future;

- Forecast accuracy decreases as the forecasting horizon increases;

- Aggregated forecasts for product groups are more accurate than individual product forecasts.

Forecasting methods may be divided into quantitative and qualitative methods. Quantitative methods require the construction of mathematical models, using historical data, that describe demand variation over time. These methods include decomposition, moving averages, exponential smoothing, ARIMA, etc.

Qualitative methods, in general, result from the opinion of process specialists to predict demand. They are frequently questioned as the systematic approach provided by quantitative techniques presents a better performance concerning future estimates. However, in cases of information scarcity, for example in the launching of new products, the experience and know-how of managers may be useful.

\subsection{Demand Forecasting Process at PR}

The data available consisted of the weekly sales from the first week of 2013 through week 17 of 2016 (Fig. 3).

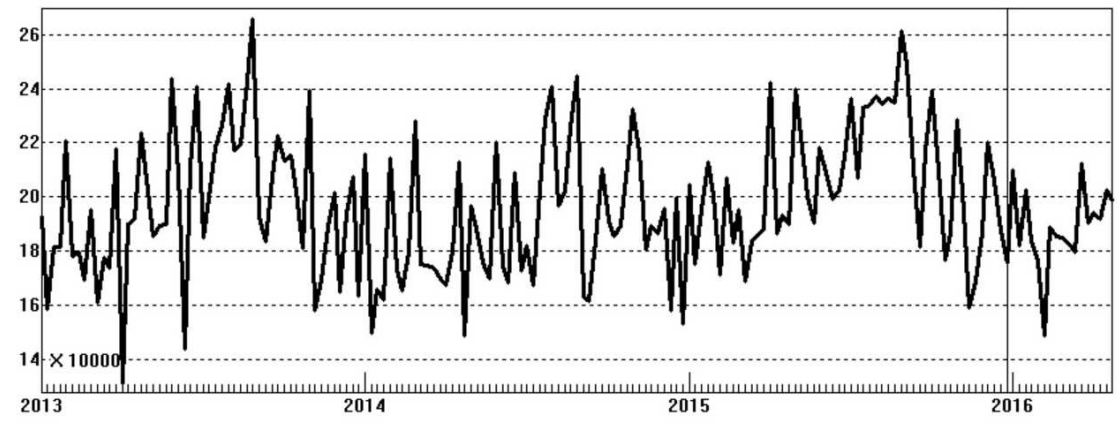

Fig. 3: Sales from week 1 of 2013 to week 17 of 2016.

We start by analyzing how the company predicts its sales in order to optimize processes and reduce unnecessary stocks or avoid lost sales.

The demand forecast performed by PR is based on a 4-week moving average. Thus in week $t$, a demand forecast for week $t+2$ is made for each product based on the actual sales concerning weeks $t-4, t-3, t-2$ and $t-1$. 
Fig. 4 shows the actual sales (black) and the forecasts obtained with the 4 -week moving average model (red).

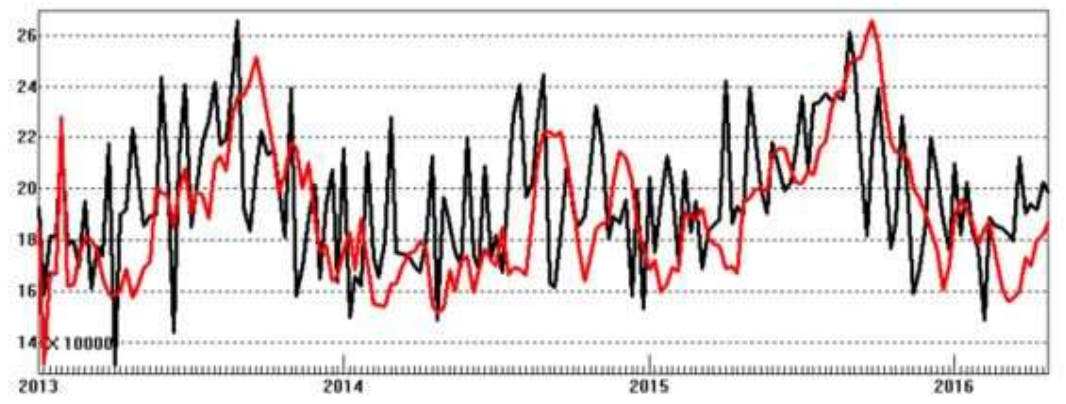

Fig. 4: Actual sales vs Forecasts using the 4 -week MA model.

The error autocorrelation function for this model is illustrated in Fig. [5.

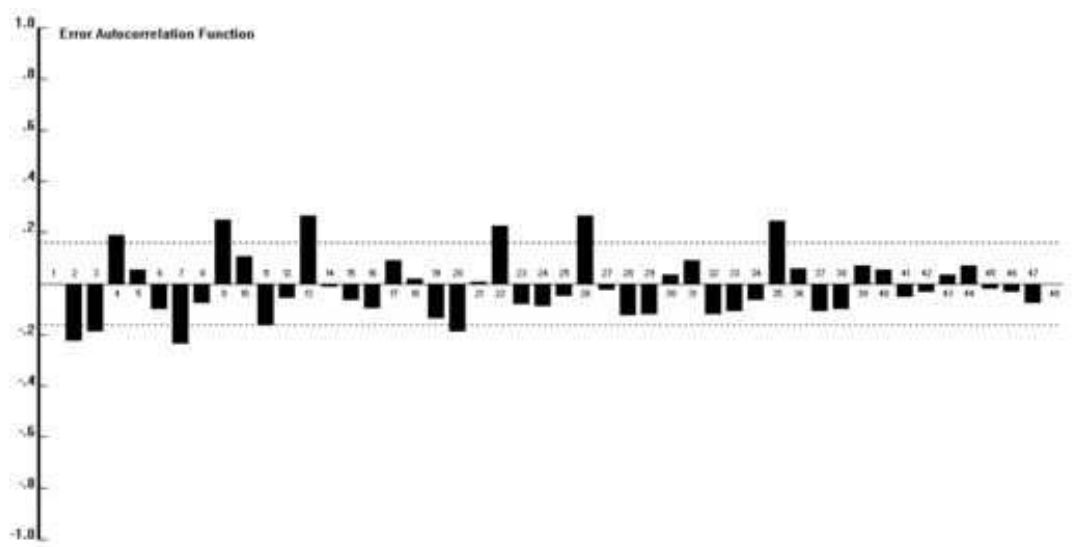

Fig. 5: 4-week MA Error Autocorrelation Function.

We evaluated the normality of the errors using Kolmogorov-Smirnov test which reveals that the errors could be considered normally distributed $(p=.200)$. This result is illustrated in Fig. 6 (Fig. 6a and Fig. 6b).

Currently, and as a form of support, the company has a file in excel format, which is updated weekly with the actual sales.

These base forecasts may be adjusted according to qualitative information obtained from its sales force. Salespeople play a key role in obtaining information for forecasts as they work very closely to customers and to the market. It is up 


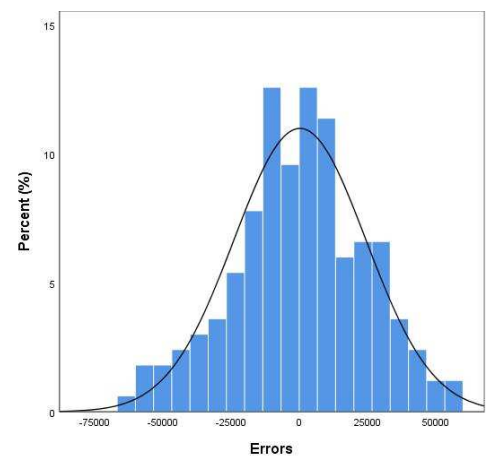

(a) Histogram of MA errors.

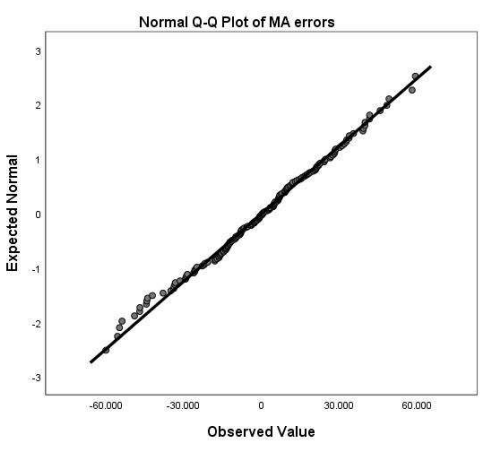

(b) QQ Plot of MA errors.

Fig. 6: Normality assumption for MA errors.

to the task manager to generate forecasts, informally collect information from the sales team in order to adjust the base forecasts, obtained from the method described.

The inputs collected from the commercial team can be of various nature. For example, a sales campaign in a particular product in a particular customer, or the exit from the market of a competing product. In this case, the sensitivity and experience of the task manager comes into play, which can increase or decrease orders to a reasonably weighted value.

Accordingly, the value of expected sales (in $\mathrm{kg}$ ), calculated on the basis of the 4-week moving average, is adjusted by the person responsible for the forecasts, which includes the inputs that he collects from the both past sales and future sales. The aim is mainly to try to decode the demand peaks of certain products and/or the low demand of them in certain weeks.

In summary, after the calculation of the base forecasts based on the 4 week moving averages (MA), in order to include all the relevant information, it becomes necessary to receive inputs from the marketing area (promotion of new products and promotional plans), commercial (customer and market data) and operational planning (capacity constraints, logistics, etc.) in order to adjust the values against these inputs.

After collection, processing and analysis phases, the final values obtained are validated once more and communicated to the production planning department.

\section{Exponential Smoothing Models}

In the moving average method described in the previous section, the forecast is determined by assigning the same weight to each of the last 4 observations available $(t-1, t-2, t-3$ and $t-4)$ and ignoring the all the all the older observations (prior to week $(t-4)$ ). 
However, it is reasonable to assume that the most recent observations contain more relevant information about what might happen in the future and therefore should have a greater weight in forecasting than the older observations. Exponential smoothing methods are based on this principle.

Exponential smoothing is one of the most popular forecasting methods. The method applies a weighted average to the observations of a time series with greater weights being given to the most recent information.

Single exponential smoothing is based on the equation 1

$$
F_{t+1}=\alpha X_{t}+(1-\alpha) F_{t}
$$

where $F_{t+1}$ is the forecast for period $t+1, \alpha$ is the smoothing constant and $X_{t}$ is the observed value for period $t$.

Since the smoothing constant varies between 0 and 1 , more weight is given to the most recent observations in determining forecasts. Its application in forecasting appears to have been pioneered in 1956 by Robert Brown. In 1957, Holt described double exponential smoothing and, in 1960, Peter R. Winters improved the algorithm by adding seasonality. This algorithm became known as triple exponential smoothing or the Holt-Winters method [13, 10.

Using data using the data from 2013, 2014 and 2015 and the Forecast Pro software we developed exponential smoothing models to forecast the first 17 weeks of 2016. The model selection criterion was the Mean Absolute Deviation (MAD), defined in equation 2 .

$$
M A D=\frac{\sum_{i=1}^{n}\left|X_{i}-F_{i}\right|}{n}
$$

where $X_{i}$ and $F_{i}$ represent, respectively, the actual sales in week $i$ and sales forecast for week $i$.

The model that minimized within sample MAD is described in the Table 1

Table 1: Exponential smoothing model selected.

\begin{tabular}{ll}
\hline Forecast Model: & Exponential smoothing: No trend, Multiplicative seasonality \\
Smoothing Weights & \\
Level: & $\alpha=0.05227$ \\
Seasonal: & $\gamma=0.3294$ \\
Mean Absolute Deviation: & $M A D=14100$ \\
\hline
\end{tabular}

Fig. 7 shows the actual sales (black) and the forecasts obtained with the selected model (red).

The error autocorrelation function for this exponential smoothing model is illustrated in Fig. 8

In addition, we evaluated the normality of the errors using KolmogorovSmirnov test which reveals that the errors could be considered normally distributed $(p=.058)$. This result is illustrated in Fig. 9 (Fig. 9a and Fig. 9b). 


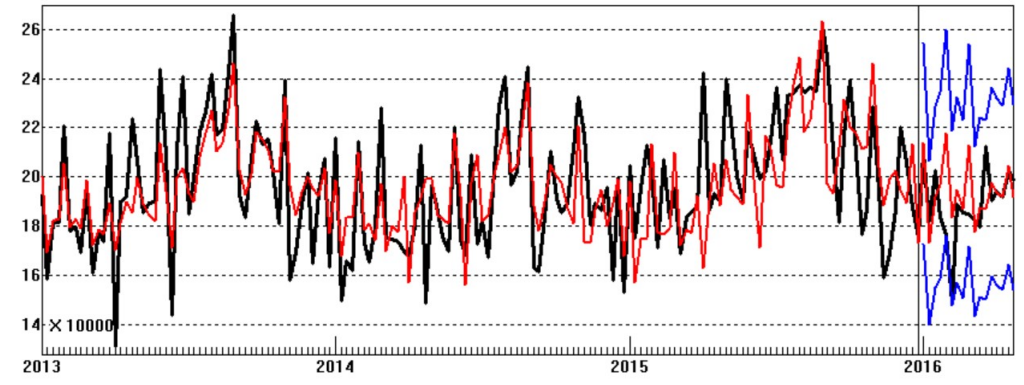

Fig. 7: Actual sales vs Forecasts using Exponential Smoothing model.

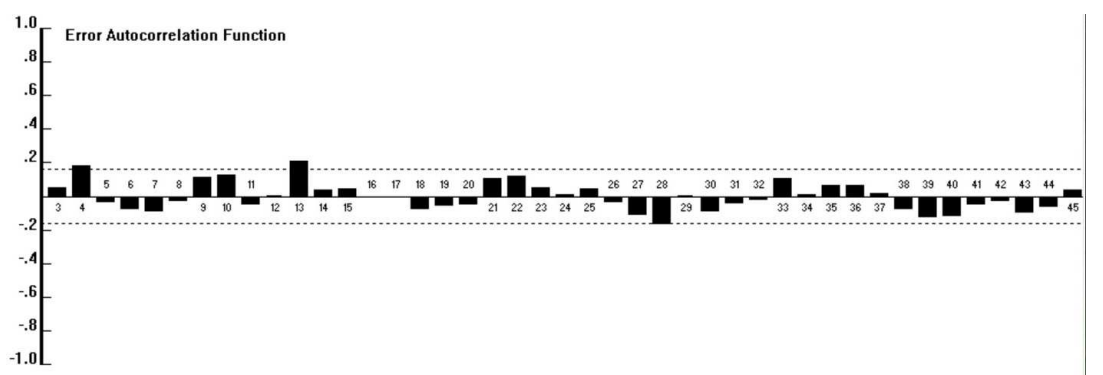

Fig. 8: Exponential Smoothing Error Autocorrelation Function.

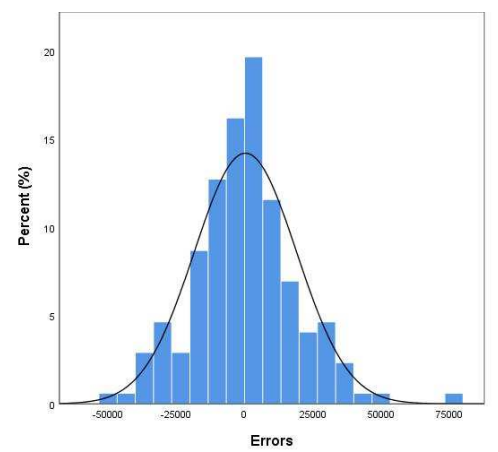

(a) Histogram of ES errors.

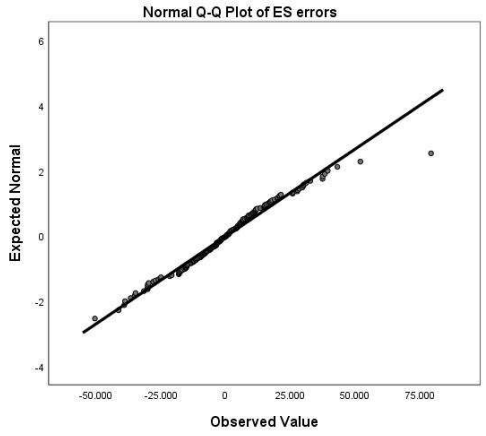

(b) QQ Plot of ES errors.

Fig. 9: Normality assumption for ES errors. 


\section{ARIMA Models}

In 1970 George Box and Gwilym Jenkins popularized ARIMA (Autoregressive Integrated Moving Average) models in their seminal textbook, Time Series Analysis: Forecasting and Control. ARIMA models generated a lot of interest in the academic community, due mostly to their theoretical foundations which proved that under certain assumptions, the models would produce optimal forecasts.

However, the Box-Jenkins methodology seemed not being widespread adopted among the business community. This was mostly due to the difficult, time consuming and subjective procedure described by Box and Jenkins to identify the proper form of the model for a given data set. Furthermore, empirical studies showed that despite the ARIMA model's theoretical superiority over other forecasting methods, in practice the models did not regularly outperform other time series methods.

Generically, a non-seasonal Box-Jenkins model is represented as ARIMA $(p, d, q)$ where $p$ indicates the number of AR terms, $d$ indicates the order of differencing, and $q$ indicates the number of MA terms. A seasonal Box-Jenkins model is symbolized as ARIMA $(p, d, q) *(P, D, Q)$, where the $p, d, q$ indicates the model orders for the short-term components of the model and $P, D, Q$ indicate the model orders for the seasonal components of the model.

We used Forecast Pro to build the ARIMA models. After transforming data in order to remove trend (using a simple difference) and seasonality (using a seasonal difference) we analysed the Autocorrelation function (ACF) and the Partial Autocorrelation function (PACF) presented in figures 10 and 11.

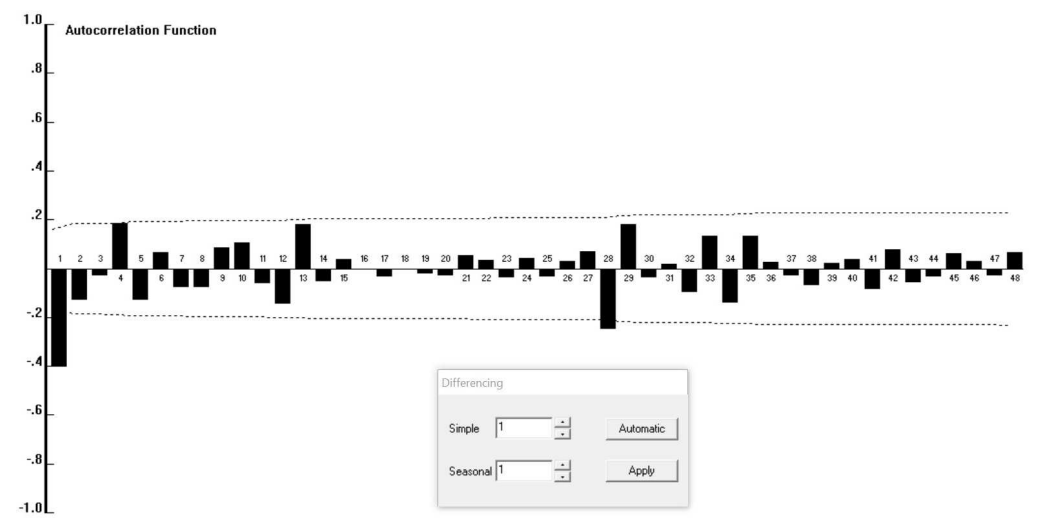

Fig. 10: Autocorrelation Function (ACF) after a simple and a seasonal difference.

This analysis lead to an $\operatorname{ARIMA}(0,1,1) *(0,1,1)^{52}$ that minimized within sample $M A D=9772$ and is summarized in Table 2 


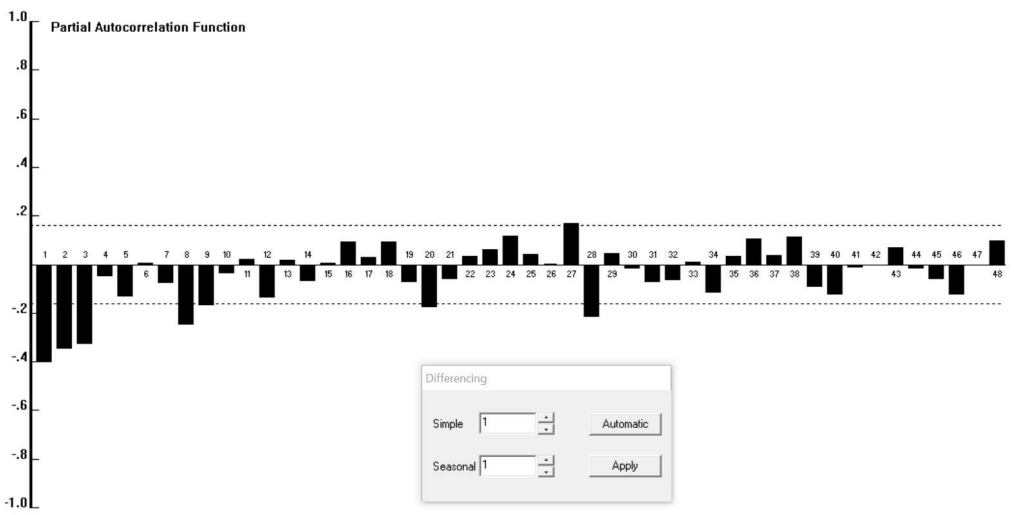

Fig. 11: Partial Autocorrelation Function (PACF) after a simple and a seasonal difference.

Table 2: ARIMA model selected . Term Coefficient Std. Error $\mid$ t-statistic

\begin{tabular}{|c|c|c|c|}
\hline$q[1[$ & 0.8878 & 0.0447 & 19.84 \\
\hline$[52$ & 0.7160 & 0.0465 & 15.38 \\
\hline
\end{tabular}

Model coefficients are significant and the Error Autocorrelation function (Fig. 12) shows that errors are random. Fig. 13 shows the actual sales (black) and the forecasts obtained with the selected model (red).

A the normality evaluation of the errors for the ARIMA model, the KolmogorovSmirnov test reveals that the errors could be considered normally distributed $(p=.063)$. This result is illustrated in Fig. 14 (Fig. 14a and Fig. 14b). 


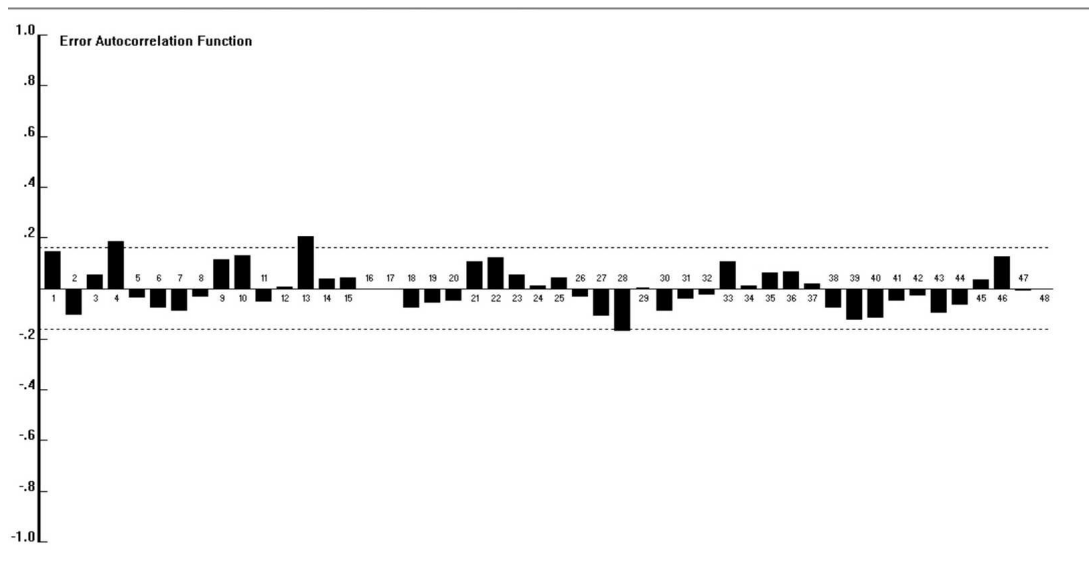

Fig. 12: Error Autocorrelation Function $(\mathrm{ACF})$ for $\operatorname{ARIMA}(0,1,1) \times(0,1,1)^{52}$.

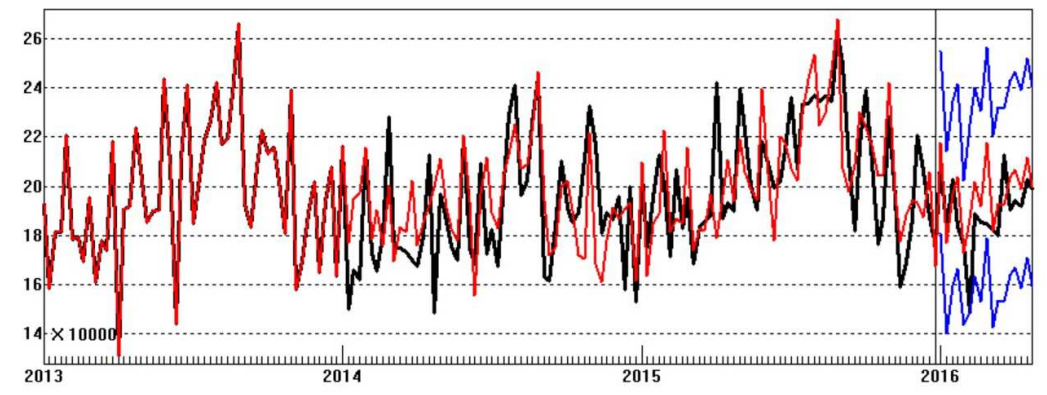

Fig. 13: Actual sales vs Forecasts using $\operatorname{ARIMA}(0,1,1) \times(0,1,1)^{52}$.

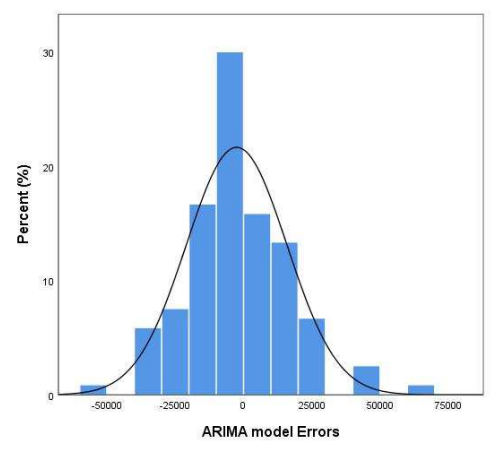

(a) Histogram of ARIMA errors.

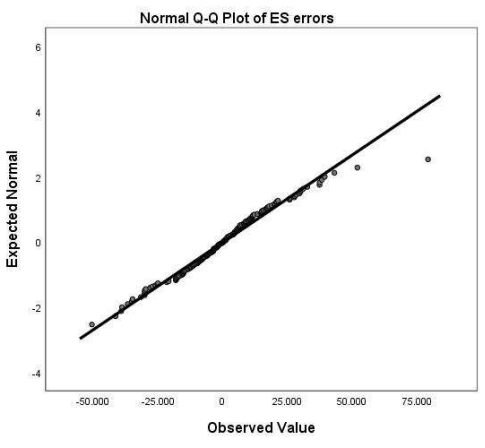

(b) QQ Plot of ARIMA errors.

Fig. 14: Normality assumption for ARIMA errors. 


\section{$5 \quad$ Forecasting Methodology Proposed}

\subsection{Combining Forecasts}

There are many reported situations where a combination of different forecasts can outperform individual forecasts.

The development of research on combining forecasts was largely documented by Clemen [5] who pointed out that "the primary conclusion of this line of research is that forecast accuracy can be substantially improved through the combination of multiple individual forecasts. Furthermore, simple combination methods often work reasonably well relative to more complex combinations".

The value of combining forecasts in an inventory management context has been reported by Chan, et al. [4, in a case study where "the results show that combining different forecasts will lead to significant improvements in demand forecasting performance and savings of around 10\% in the amount of safety stock that will need to be carried".

\subsection{Combining methods}

Although a significant amount of research has been published on combining forecasts, the choice of which method should be used in a particular situation is not al-ways clear. Over the last forty years, many combining methods have been proposed. These methods range from the simple average to much more sophisticated approaches to determine optimal combinations.

The simple average is reported to perform well in many published studies. The simple average has the advantage of being uncomplicated and robust which, in a context where hundreds or thousands of items have to be periodically forecast, is a very attractive feature.

Another approach, known as outperformance, Bunn [3], gives different weights to the individual forecasts. Each weight is made proportional to the probability that the respective forecasting method will have the best individual performance. Each probability may be estimated on the basis of past performance of the alternative forecast methods, and can be revised using a Bayesian analysis. It has the advantage of being robust and having an intuitive meaning. Bates \& Granger 2. proposed an approach where weights are calculated in order to minimise the error variance of the combination, assuming that each individual forecast is unbiased. Granger \& Ramanathan [9] showed that this method is equivalent to a least squares regression in which the constant is suppressed and the weights are constrained to sum to one. They proposed a regression method, where individual forecasts are used as regressors, and the combining weights are not restricted, arguing that this has the advantage of producing an unbiased combined forecast even when individual forecasts are biased.

However this has been questioned by a number of researchers. The theoretical work by Diebold [6] implies that using unrestricted least squares regression to combine forecasts will lead to serially correlated errors. His recommendation was to restrict the coefficients to sum to one. The same conclusion was made by de 
Menezes \& Bunn [12] in a study to investigate the issue of serial correlation in combining methods.

\subsection{Combining results}

It seems that there is still considerable disagreement concerning the best choice of combining rule. However, the M-Competition, a large scale forecasting competition with 1001 time-series, Makridakis et al. [1] and many other applications, Clemen [5] and Genre et al. [8, gave strong support for the simple average. This strong performance of the simple average may be due, as suggested by some authors, to the instability of "optimal" weights, resulting from changes in the individual forecast methods' performance over time. This may explain why a simple average, although having sub-optimal weights, may produce consistently good results.

We used a simple average to combine the three different sets of forecasts available (the 4-week moving average used by the company, the exponential smoothing and the ARIMA models developed), and compared the performance of these combined fore-cast with forecasts obtained with the model used by the company (described in section 2.2). The combined forecasts reduced the MAD by $22 \%$ (from 11826 to 9219 ), the MAPE by $21 \%$ and the MSE by $27 \%$. These results are shown in Table 3 .

Table 3: Model performance comparison.

\begin{tabular}{|c|c|c|c|c|c|}
\hline 2016 & $\begin{array}{c}\text { Observed } \\
\text { Values }\end{array}$ & $\begin{array}{c}\text { Company } \\
\text { forecasts }\end{array}$ & $\begin{array}{c}\text { Exp. Smooth. } \\
\text { forecasts }\end{array}$ & $\begin{array}{c}\text { ARIMA } \\
\text { forecasts }\end{array}$ & $\begin{array}{c}\text { Combined } \\
\text { forecasts }\end{array}$ \\
\hline 1 & 210170 & 195563 & 213706 & 217858 & 209042 \\
2 & 182101 & 200109 & 173385 & 177080 & 183525 \\
3 & 202687 & 197375 & 191788 & 196982 & 195382 \\
4 & 183538 & 194809 & 196571 & 203926 & 198435 \\
5 & 176603 & 188812 & 217957 & 172769 & 193179 \\
6 & 148692 & 192680 & 183446 & 186774 & 187633 \\
7 & 188945 & 194624 & 194643 & 201630 & 196966 \\
8 & 185514 & 186232 & 186930 & 191736 & 188299 \\
9 & 184927 & 177880 & 212852 & 217607 & 202780 \\
10 & 182538 & 174445 & 177823 & 181638 & 177969 \\
11 & 179680 & 174939 & 187624 & 192807 & 185123 \\
12 & 212595 & 177020 & 186711 & 192316 & 185349 \\
13 & 190533 & 185481 & 197910 & 203552 & 195648 \\
14 & 194113 & 183165 & 193957 & 206776 & 194633 \\
15 & 191991 & 189935 & 191605 & 198666 & 193402 \\
16 & 202631 & 191337 & 204498 & 211532 & 202456 \\
17 & 198675 & 194230 & 191943 & 199927 & 195367 \\
\hline & $M A D$ & 11826 & 11905 & 12301 & 9219 \\
& $M A P E$ & $6.49 \%$ & $6.60 \%$ & $6.77 \%$ & $5.16 \%$ \\
& $M S E \times 10^{8}$ & 2.65 & 2.92 & 2.53 & 1.94 \\
\hline
\end{tabular}




\section{Conclusions}

In an increasingly competitive market, where companies are fighting for market shares that are hard to achieve, the pursuit of operational efficiency as a competitive advantage is essential. The volatility of the markets makes planning and replanning an endless task, in order to respond to more demanding customers. As a result, the pursuit of process optimization as a way to ensure better results is a major focus of attention.

This study allowed the formulation of some conclusions about the demand forecasting process in the company.

The exponential smoothing and the ARIMA models developed using Forecast Pro software demonstrated its applicability, being the results considered satisfactory and able to serve as the basis for the company to predict demand.

It has been shown that combining these forecasts improves significantly accuracy. Simple approaches to combining provide adequate results and combining methods can be used with little increase in cost. Therefore on the basis of simplicity and efficiency, we believe that the simple average of the forecasts produced by the three different models ( 4 -week moving average, exponential smoothing and ARIMA), may provide a good solution for this forecasting problem.

In addition to the model performance against the current methodology applied by the company, other advantages can be pointed out, such as the fact that this is a more robust methodology able in a timely manner to generate demand forecasts, releasing in this way the managers of this task, so that they can provide more time for the analysis of scenarios and to improve the decisions taken in this area.

\section{References}

1. Acar, Y., Gardner, E.S.: Forecasting method selection in a global supply chain. International Journal of Forecasting 28(4), 842-848 (2012). https://doi.org/10.1016/j.ijforecast.2011

2. Bates, J.M., Granger, C.W.J.: The combination of forecasts. OR 20(4), 451-468 (1969)

3. Bunn, D.W.: A bayesian approach to the linear combination of forecasts. Operational Research Quarterly (1970-1977) 26(2), 325-329 (1975)

4. Chan, C.K., Kingsman, B.G., Wong, H.: The value of combining forecasts in inventory management - a case study in banking. European Journal of Operational Research 117(2), 199 - 210 (1999). https://doi.org/https://doi.org/10.1016/S0377-2217(98)00277-X

5. Clemen, R.T.: Combining forecasts: A review and annotated bibliography. International Journal of Forecasting 5(4), 559 - 583 (1989). https://doi.org/https://doi.org/10.1016/0169-2070(89)90012-5

6. Diebold, F.X.: Serial correlation and the combination of forecasts. Journal of Business \& Economic Statistics 6(1), 105-111 (1988). https://doi.org/10.1080/07350015.1988.10509642

7. Gaither, N., Frazier, G.: Administração da Produção e Operações. Thomson Learning (2007) 
8. Genre, V., Kenny, G., Meyler, A., Timmermann, A.: Combining expert forecasts: Can anything beat the simple average? International Journal of Forecasting 29(1), 108-121 (2013). https://doi.org/10.1016/j.ijforecast.2012

9. Granger, C.W.J., Ramanathan, R.: Improved methods of combining forecasts. Journal of Forecasting 3(2), 197-204 (1984). https://doi.org/10.1002/for.3980030207

10. Holt, C.C., Modigliani, F., Muth, J.F., Simon, H.A., Bonini, C.P., Winters, P.R.: Planning Production, Inventories, and Work Force. Prentice-Hall (1960)

11. Makridakis, S., Andersen, A., Carbone, R., Fildes, R., Hibon, M., Lewandowski, R., Newton, J., Parzen, E., Winkler, R.: The accuracy of extrapolation (time series) methods: Results of a forecasting competition. Journal of Forecasting 1(2), 111-153 (1982). https://doi.org/10.1002/for.3980010202

12. de Menezes, L.M., Bunn, D.W.: The persistence of specification problems in the distribution of combined forecast errors. International Journal of Forecasting 14(3), 415-426 (September 1998)

13. Winters, P.R.: Forecasting sales by exponentially weighted moving averages. Manage. Sci. 6(3), 324-342 (Apr 1960). https://doi.org/10.1287/mnsc.6.3.324

14. Wong, W., Guo, Z.: A hybrid intelligent model for medium-term sales forecasting in fashion retail supply chains using extreme learning machine and harmony search algorithm. International Journal of Production Economics 128(2), 614-624 (December 2010) 